
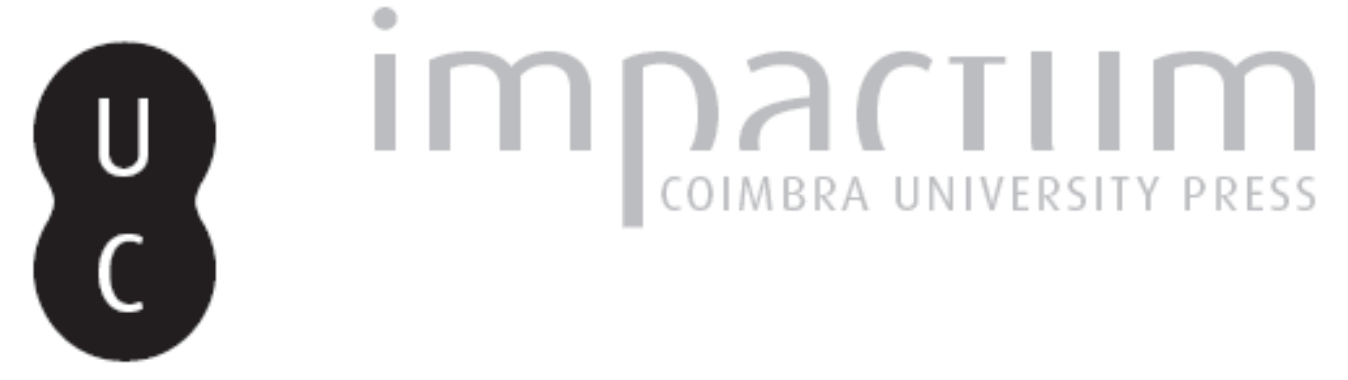

\title{
As dunas de Quiaios e o risco de incêndio: uma breve reflexão
}

\section{Autor(es): $\quad$ Almeida, António Campar de}

Publicado por: Associação Portuguesa de Riscos, Prevenção e Segurança

URL persistente:

URI:http://hdl.handle.net/10316.2/40161

DOI:

DOl:https://doi.org/10.14195/1647-7723_3_2

Accessed : $\quad$ 26-Apr-2023 15:53:44

A navegação consulta e descarregamento dos títulos inseridos nas Bibliotecas Digitais UC Digitalis, UC Pombalina e UC Impactum, pressupõem a aceitação plena e sem reservas dos Termos e Condições de Uso destas Bibliotecas Digitais, disponíveis em https://digitalis.uc.pt/pt-pt/termos.

Conforme exposto nos referidos Termos e Condições de Uso, o descarregamento de títulos de acesso restrito requer uma licença válida de autorização devendo o utilizador aceder ao(s) documento(s) a partir de um endereço de IP da instituição detentora da supramencionada licença.

Ao utilizador é apenas permitido o descarregamento para uso pessoal, pelo que o emprego do(s) título(s) descarregado(s) para outro fim, designadamente comercial, carece de autorização do respetivo autor ou editor da obra.

Na medida em que todas as obras da UC Digitalis se encontram protegidas pelo Código do Direito de Autor e Direitos Conexos e demais legislação aplicável, toda a cópia, parcial ou total, deste documento, nos casos em que é legalmente admitida, deverá conter ou fazer-se acompanhar por este aviso.

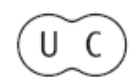




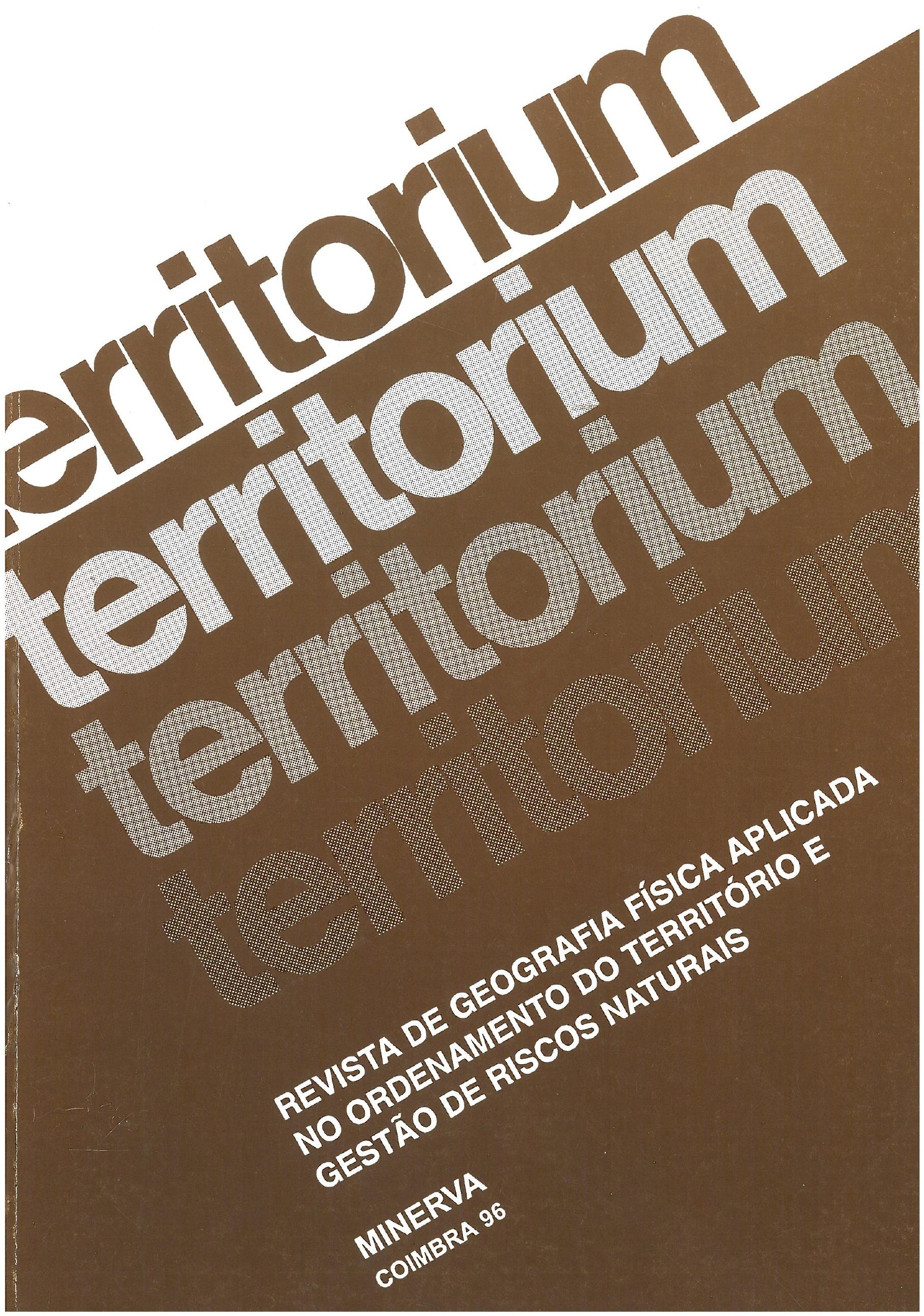




\title{
As Dunas de Quiaios e o risco de incêndio. Uma breve reflexão
}

\author{
António Campar de Almeida*
}

\author{
Resumo: \\ Relativamente ao sistema dunar de Quiaios, ainda activo no início do século e que, para ser fixo, foi sujeito à \\ sementeira de um pinhal, discute-se agora o modo como obstar à propagaçăo dos incêndios florestais, o seu novo \\ risco. Preconiza-se a plantação de folhosas higrófilas nas depressōes interdunares. \\ Palavras-chave: \\ Quiaios, dunas, pinhal, folhosas, incêndios, riscos.
}

Résumé:

En ce qui concerne le système dunaire de Quiaios, encore actif au début du siècle et qui, pour devenir stable, a été soumis à la semaille d'une pinède, on discute maintenant la meilleure façon d'éviter la propagation des indendies forestiers, son nouveau risque. On propose la plantation de feuillus hygrophiles dans les dépressions interdunaires.

Mots clés:

Quiaios, dunes, pinède, feuillus, incendies, risques.

\section{Abstract:}

The Quiaios dune system was still active at the beginning of the century. In order to become stable, a pine-planting system was implemented. Nowadays, the discussion is centered around ways of stopping the spreading of forest fires, its new risk. The planting of hygrophilous deciduous trees is advised on the dune depressions.

Key words:

Quiaios, dunes, pine forest, deciduous trees, fires, risks.

\section{Introdução}

Com esta nota pretende-se expressar alguma da reflexão que as Dunas de Quiaios nos têm suscitado nos últimos tempos, "nomeadamente, sobre a sua dinâmica passada e presente enquanto condicionadora, de algum modo, das actividades humanas consigo relacionadas, directa ou indirectamente.

Sendo um ecossistema bastante instável, na sua origem e posterior desenvolvimento, quase sempre actuou como um factor de risco para as populações suas vizinhas (1), por ser composto por areias que facilmente avançavam sobre os terrenos agrícolas adjacentes. Essa frequente e fácil movimentação das areias ao longo de todo o campo de dunas, conseguia destruir grande parte da pouca vegetação existente e obstar à instalação de nova vegetação capaz de travar

\footnotetext{
* Instituto de Estudos Geográficos. Faculdade de Letras. Universidade de Coimbra

(1) Pelo menos desde que a negligência humana, ou a sua necessidade, fizeram escassear a vegetação natural que o compunha
}

o seu avanço (Foto 1). Ainda no início deste século, até aos anos vinte, as dunas se mostravam indomáveis e corriam céleres para o interior (M. A. REI, 1940).

Foi com o intuito de parar com esta ameaça constante que o Regente Florestal Manuel Alberto Rei levou a cabo a empresa de arborizar todo este espaço dunar a Norte da Serra da Boa Viagem, nas décadas de vinte e de trinta, fixando definitivamente as areias. A inexistência de solo limitou-lhe a possibilidade de escolha de espécies adaptadas a este meio, peloque recorreu, quase em exclusividade, ao pinheiro bravo, árvore rústica e apta a desempenhar o papel fundamental de ser pioneira. Em simultâneo, mandou semear espécies subarbustivas próprias das areias litorais, como o estorno, na duna primária, a camarinheira, a sargaça, a sargacinha, o tojo, etc., e algumas arbustivas, como as acácias e o samouco, espécies que ajudariam, em especial nos primeiros tempos de fraco desenvolvimento dos pinheiros, a segurar as areias e a evitar o soterramento daqueles enquanto juvenis. 
Foto I - Dunas antes de serem plantadas, perfeitamente limpas de vegetação e às quais os raros pinheiros pouco ou nenhum obstáculo oferecian ao seu avanço: anos vinte. (Folo gentilnente cedida pela $S r^{3}$ Eng ${ }^{2}$ Antónia Rei Sampaio, neta de M. Alberto Rei.)

\section{Muda-se a estrutura, muda-se a dinâmica}

Passadas algumas décadas, o que se apresenta à vista de todos é um extenso pinhal, ondulante em sintonia com a ondulação das dunas, mas nem sempre de igual crescimento. Em regra, os pinheiros desenvolveram-se melhor nas áreas aplanadas, no cimo e na base das dunas; em muitas vertentes das dunas e nas depressões interdunares, os pinheiros têm maior dificuldade em crescer (A. C. ALMEIDA, 1995). Seja como for, os objectivos que se pretendiam alcançar com a sementeira do pinhal haviam sido plenamente concretizados - a estabilização das dunas e o correspondente fim do risco de movimentação das areias.

Entretanto, a um período de construção e movimentação de dunas, protagonizado, obviamente, pelo vento, segue-se um período de destruição paulatina das mesmas, à custa da actuação da escorrência e do "splash", emespecial nas manchas com menor cobertura por parte de plantas dos estratos muscíneo, herbáceo e subarbustivo (idem, ibidem). A progressiva acumulação de matéria orgânica sobre as areias, veio permitir o desenvolvimento de um solo que, apesar de muito pouco evoluído - é, em regra, um regossolo - começa a ser um dos suportes principais da estabilidade de todo este sistema dunar.

Salvo algumas raras excepções, localizadas em especial próximo de Mira, a mata é constituída por uma única espécie de exploração silvícola que é o pinheiro bravo. Ora, uma extensão de mais de $30 \mathrm{~km}$ por 5 a $6 \mathrm{~km}$ de largura de uma mata monoespecífica, ainda por cima altamente combustível, vem introduzir outro tipo de risco a este campo de dunas - o fogo florestal. Julho de 1993 foi um dos excmplos melhor ilustrativos desta realidade.

O incêndio, iniciado na lixeira municipal de Mira, propagou-se pela mata das dunas em direcção a Sul. Depois de ter sido dado como extinto, de se ter

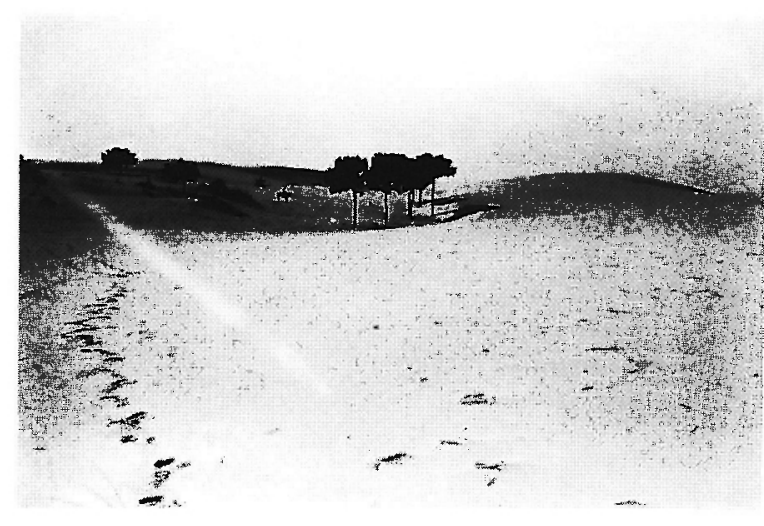

reacendido várias vezes e de ter tomado vários rumos de progressão, em função dos ventos dominantes (de Norte nos primeiros dias e de Este no último), veio a findar definitivamente junto da estrada florestal Lagoa das Braças - Costinha, quando o vento passou a soprar de Oeste, com maior grau de humidade (L. LOURENÇO, A. NUNES e F. REBELO, 1994).

Apesar da existência de uma rede de aceiros e de arrifes e de algumas estradas florestais, estes mostraram-se ineficazes na paragem das chamas. Os aceiros e arrifes para além de dividirem a mata em talhões ${ }^{2)}$ não parecem poder exercer outra função, já que a acidentada topografia das dunas e o tipo de viaturas que os Bombeiros empregam no combate aos incêndios, não permitem a sua utilização como vias de penetração da mata e de aproximação das chamas, de modo a mais rapidamente as combater. Só as estradas florestais podem desempenhar esse papel; mas, se forem estreitas, com as copas das árvores quase a tocarem-se e se a sua rede for demasiado rara, como é o caso nesta mata, decerto que a sua eficácia como obstáculo à propagação dos incêndios está bastante comprometida. Entre Quiaios e a Praia da Tocha, por exemplo, apenas existe uma estrada florestal longitudinal, a meio da mata, distando em média $3 \mathrm{~km}$ da praia, e duas transversais completas, afastadas entre si de $8 \mathrm{~km}$, mais uma transversal de Morros até à florestal do meio da mata, distante $5 \mathrm{~km}$ da transversal da Lagoa das Braças, e outra transversal que liga esta lagoa até à Casa da Guarda de Quiaios, prolongando-se por mais 1,5 km em direcção ao mar. Ou seja, há áreas inacessíveis a veículos de ataque às chamas até $1,5 \mathrm{~km}$ de distância, na metade interior e até cerca de $3 \mathrm{~km}$ na metade ocidental da mata. É urgente encurtar estas distâncias por meio do aumento da rede de estradas florestais.

(2) Os arrifes distam entre si de $300 \mathrm{~m}$ e os aceiros de $600 \mathrm{~m}$. 
Porém, há que ter em atenção o risco de ser fomentado o acesso de pessoas, com as suas viaturas, a um maior número de pontos da praia até então inacessíveis, se essas vias de penetração atingirem ou se aproximarem demasiado da duna primária. Neste caso, esta seria fragilizada por pisoteio, ou outros processos, como sempre acontece quando um significativo número de pessoas tem acesso à praia. A construção das estradas até uma distância suficientemente desencorajadora para as pessoas se atreverem a frequentar aqueles pontos da praia, por exemplo até quinhentos metros da duna primária, talvez fosse uma medida preventiva.

\section{Diversidade - outra luta possível}

Opapel desempenhado pelo pinheiro bravo, ajudado pelas suas acompanhantes arbustivas, subarbustivas e herbáceas, como fixador das dunas foi coroado de êxito - mesmo depois do incêndio de 1993, as areias das dunas não se movimentaram. Os restos não ardidos das plantas, as cinzas e, principalmente, os subarbustos que rebentaram, ou germinaram, depois das primeiras chuvas e o solo desenvolvido ao longo dos últimos 60 anos, mantiveram praticamente intactas as dunas.

É legítimo que a fase seguinte seja dedicada, essencialmente, à produção. Para tal é importante adaptar a produção às potencialidades destas areias ocupando-as, sempre que seja viável, com as espécies melhor adaptadas às diversas condições que aquelas oferecem. O pinheiro bravo nem sempre se desenvolve

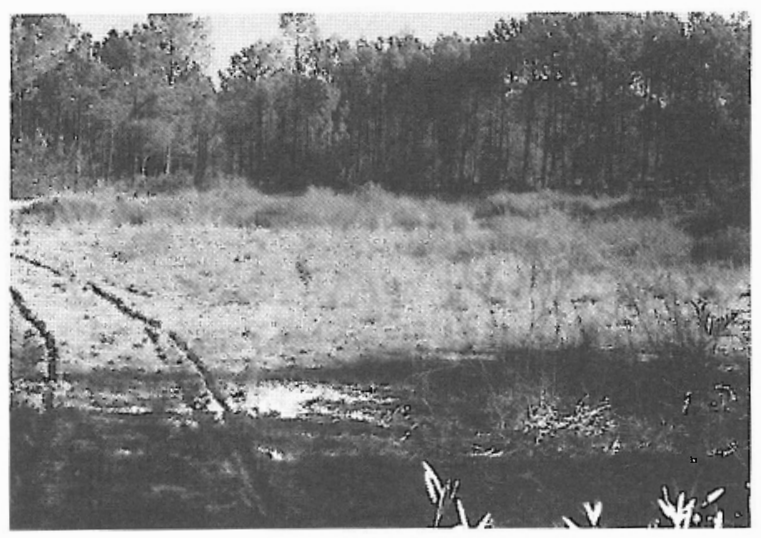

satisfatoriamente, como se pode verificar em algumas vertentes das dunas e no fundo das depressões interdunares (Foto 2)

Para ultrapassar este óbice devem ser ensaiadas outras espécies que possam responder melhor àquelas condiçōes. Sobre dunas em que o pinheiro bravo mostra mais dificuldades podia-se tentar o pinheiro manso, a espécie que, segundo alguns autores ${ }^{(3)}$, formaria a cobertura natural destas areias. Em termos de risco de incêndio pouco ou nada melhoraria, pelo facto de ser, também, uma resinosa, mas, pela forte sombra que emite, pelo menos ajudaria a manter o sub-bosque raro.

Algumas espécies arbóreas exóticas podiam ser ensaiadas. Uma das que parecem dar bons resultados é a Casuarina ${ }^{4}$, espécie australiana, pouco exigente quanto a solos. Mas, por que não tentar introduzir folhosas da nossa flora como o sobreiro, por exemplo? Se se desenvolvesse satisfatoriamente traria todas as vantagens quanto à composição paisagística e à luta contra os incêndios, por ser uma pirófita. Aliás, o próprio M. Alberto Rei admitia a sua utilização neste meio ao considerar que o sobreiro "vive quase igualmente em todos os solos, até mesmo nas areias do litoral" (M. A. REI, 1914, p. 83).

No entanto, pensamos que a grande esperança da diversificação desta mata reside na ocupação das depressões interdunares, em função das suas condições hidrológicas próprias. No final do Verão de 1995, terminus de um período de três anos secos, verificámos a manutenção de humidade nas areias do fundo de várias depressões, humidade correspondente a 2-3\% do pesoem água, a partir de 1 a $40 \mathrm{~cm}$ de profundidade. De igual modo, a toalha freática achava-se entre 1,10 e 2,25 m de profundidade, ou seja, suficientemente próxima da superfície para ser alcançada pelas raízes de espécies arbóreas higrófilas. Em regra, as depressões onde estas condiçōes se verificam, registam a presença de espécies herbáceas higrófilas-Schoenus nigricans

Foto 2 - Depressão interdunar coberta por Ciperáceas e algumas outras espécies higrófilus, na actualidade.

L. eScirpusholoschoenus L.. Quando surgiaSchoenus nigricans $\mathrm{L}$. a toalha freática não descia para além de $2 \mathrm{~m}$; quando apenas ocorria Scirpus holoschoenus L. a toal ha já podia ultrapassar os 2,20 $\mathrm{m}$ de profundidade.

(3) Como por exemplo R. CHODAT (1913) e A.T. MORAIS (1940) 
No fundo destas depressões interdunares poderia ser ensaiada a introdução de espécies arbóreas ripícolas que sejam, também, pouco exigentes quanto aos solos. O amieiro [Alnus glutinosa (L.) Gaertner], ripícola, passível de se desenvolver em terrenos relativamente secos (A. QUARTIER e P. BAUER, 1973) e que também tem a vantagem de ser enriquecedora dosoloem azoto, podia ser tentada nas depressões com Schoenus nigricans L. Nestas mesmas depressões poder-se-iam experimentar também os choupos, tanto o Populus nigra L. como o Populus alba L., ripícolas da nossa flora ou, por que não, choupos híbridos, como aconselhou A.M. Azevedo Gomes (1969) para as depressões das dunas do litoral alentejano. Uma exótica, o tulipeiro da Virgínia (Liriodendron tulipifera L.) que se adapta a condições semelhantes às do choupo negro (A.M. GOMES, s. d.), também podia ser experimentada nestas depressões.

Nas depressões dominadas pelo Scirpus holoschoenus L., para além daquelas espécies, poderiam ser ensaiadas espécies como o freixo (Fraxinus angustifolia L.), já introduzido junto à Lagoa das Braças, com algum sucesso, assim como o plátano (Platanus hybrida Brot.) de que podem ser vistos alguns exemplares junto da Vala da Lavadia, com alturas de 6 a $8 \mathrm{~m}$.

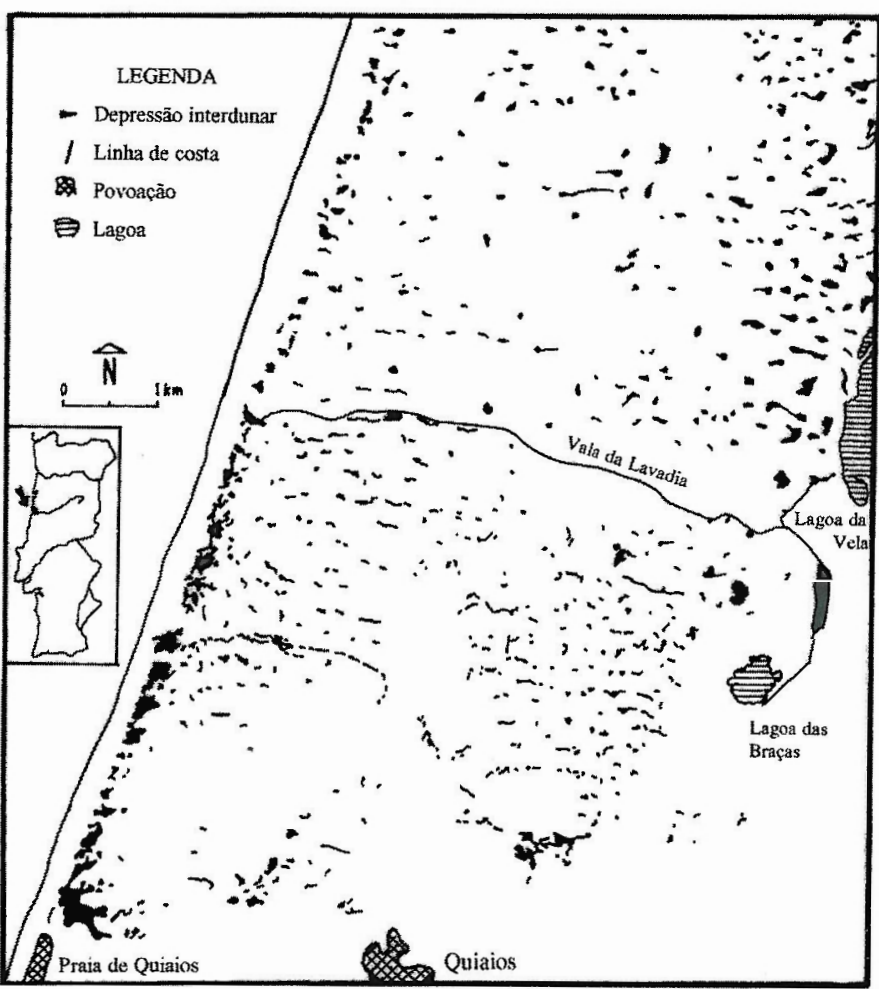

Se fosse possível a plantação de uma boa parte destas depressões, com as folhosas indicadas, ir-se- ia assistir a uma compartimentação arbórea automática desta mata, em função da distribuição relativamente regular das depressões por este campo de dunas (Fig. 1). Decerto que a velocidade de propagação de um eventual incêndio seria significativamente afrouxada e, portanto, as consequências e o próprio risco de incêndio baixariam bastante.

$\mathrm{Na}$ área ardida em 1993 não foi feita qualquer intervenção com o objectivo de reconstituir a mata, sendo esta deixada a uma reconstituição natural. Esta far-se-á, decerto, à custa do pinheiro bravo e, eventualmente, por acácias. Com alguma sorte, aqui e além reaparecerão exemplares de samouco. Mais uma razão para ser compartimentada com folhosas que, concerteza, compensaria o esforço e despesa dispendidos.

\section{REFERÊNCIAS BIBLIOGRÁFICAS}

ALMEIDA, A.Campar (1995)- Danas de Quicios, Gândara e Serra da Boa Viagem. Uma abordagem ecológica da paisagem. Fac. Letras, Coimbra, 305 p. (policopiado).

CHODAT, R. (1913) - "Voyages d'études géobotaniques au Portugal", in Le Globe, t. LII.

Fig. I - Depressōes interdunares, com manutençāo de uma certa humidade, detectadas nas Dunas de Quiaios, a partir da fotografia aérea na escala aproximada de $1 / 30000$ (voo de 1979, Instituto Geográfico e Cadastral).

GOMES, A. M. Azevedo (s. d.) - Primeiras noçōes de Dendrologia Florestal. Textos de Formação Profissional, Sec. Est. Agricultura (policopiado).

GOMES, A. M. Azevedo (1969) - Fomento da arborização nos terrenos particulares. (Planeamento para Sul do Tejo). F. C. Gulbenkian, Lisboa.

LOURENÇO, L., Nunes, Adélia e Rebelo, Fernando (1994) - "Os grandes incêndios florestais registados em 1993 na fachada costeira ocidental de Portugal Continental". Territorium, I, pp. 43-61.

MORAIS, Artur Taborda de (1940) - "Novas áreas da fitogeografia portuguesa", Bol. Soc. Broteriana, Coimbra, XIV (Il Série), pp. 97-138.

QUARTIER, A. e BAUER-BOVET, P. (1973) - Guide des arbres et arbustes d'Europe. Ed. Delachaux et Niestlé, Neuchâtel.

REI, M. Alberto (1914) - Arborização e Agricultura. Associação d'Instrução Popular, Figueira da Foz.

REI, M. Alberto (1940) - Arborização. Alguns artigos de propaganda regionalista. Figueira da Foz. 